\title{
Synthesis and Optical Properties of $\mathrm{Cu}_{2} \mathrm{O}$ and $\mathrm{Au}-\mathrm{Cu}_{2} \mathrm{O}$ Core-shell Particles
}

\author{
Sai Cong Doanh, Pham Nguyen Hai, Ngac An Bang* \\ Faculty of Physics, VNU University of Science, 334 Nguyen Trai, Hanoi, Vietnam
}

Received 22 Septemberl 2017

Revised 33 October 2017; Accepted 25 October 2017

\begin{abstract}
Cuprous oxide $\left(\mathrm{Cu}_{2} \mathrm{O}\right)$ and $\mathrm{Au}-\mathrm{Cu}_{2} \mathrm{O}$ core-shell nanoparticles were successfully synthesized using the chemical reduction method. The morphology of the synthesized pure $\mathrm{Cu}_{2} \mathrm{Oparticles}$ can be controlled by varying the amount of reducing agent $\mathrm{NH}_{2} \mathrm{OH} . \mathrm{HCl}$. Due to their similar crystal structure and relatively small lattice mismatch $\mathrm{Cu}_{2} \mathrm{O}$ particles are nucleated and locally undergo an epitaxial growth on the surface of the multi-faceted Au seed resulting in a stellated icosahedra Au- $\mathrm{Cu}_{2} \mathrm{O}$ core-shell particle. The extinction spectrum of $\mathrm{Cu}_{2} \mathrm{O}$ particles offew hundred-nm in size is dominated by light scattering, while that of the stellated icosahedra $\mathrm{Au}$ $\mathrm{Cu}_{2} \mathrm{O}$ core-shell particles exhibits the interband absorption of the $\mathrm{Cu}_{2} \mathrm{O}$ shell only. The interband absorption peak undergoes a blue shift as the shell gets thinner. No prominent SPR of the Au nanocore was observed due to a rather thick $\mathrm{Cu}_{2} \mathrm{O}$ shell.
\end{abstract}

Keywords: $\mathrm{Cu}_{2} \mathrm{O}$ nanoparticle, $\mathrm{Au}-\mathrm{Cu}_{2} \mathrm{O}$ core-shell nanoparticle, Surface Plasmon Resonance (SPR).

\section{Introduction}

Cuprous oxide is one of the earliest discovered direct band gap semiconductor with a band gap energy of $2.1 \mathrm{eV}[1,2]$, which makes it a promising material for applications in various fields such as sensor [3], photocatalysis [4], photoactivated water splitting [5] and lithium ion batteries [6]. In the last decade, $\mathrm{Cu}_{2} \mathrm{O}$ nanostructures have attracted significant attention because many interesting properties were enhanced greatly due to surface and quantum effects. Different micro and nanostructures of $\mathrm{Cu}_{2} \mathrm{O}$ such as nanocube [7], octahedral [8] and other symmetrical structures have been synthesized and studied but nano-heterostructures of $\mathrm{Cu}_{2} \mathrm{O}$ are only studied recently. Such heterostructures have shown many promising applications in photo-catalysis and electrochemical applications.

In this report, $\mathrm{Cu}_{2} \mathrm{O}$ and $\mathrm{Au}-\mathrm{Cu}_{2} \mathrm{O}$ core-shell particles were synthesized by chemical reduction method. The synthesized samples were then subjected to characterizations such as XRD, FESEM, TEM and optical absorption analysis.

\footnotetext{
*Corresponding author. Tel.: 84-912445352.

Email: ngacanbang@hus.edu.vn

https//doi.org/ 10.25073/2588-1124/vnumap.4233
} 


\section{Experimental}

Spherical gold nanoparticles were synthesized and then used as the core for the fabrication of $\mathrm{Au}$ $\mathrm{Cu}_{2} \mathrm{O}$ core-shell particles. The synthesis procedure of the gold nanoparticles was reported in detail elsewhere [9]. $\mathrm{Cu}_{2} \mathrm{O}$ and $\mathrm{Au}-\mathrm{Cu}_{2} \mathrm{O}$ core-shell nanoparticles were fabricated using the technique reported in [10-13]. In a typical synthesis procedure of $\mathrm{Cu}_{2} \mathrm{O}$ particles, an amount of $0.87 \mathrm{~g}$ Sodium Dodecyl Sulfate (SDS $-\mathrm{C}_{12} \mathrm{H}_{25} \mathrm{NaO}_{4} \mathrm{~S}$ ) was dissolved in $(9.05-x) \mathrm{ml}$ of DI water. Volumes of $0.1 \mathrm{ml}$ of $0.1 \mathrm{M} \mathrm{CuCl}_{2}, 0.25 \mathrm{ml}$ of $1.0 \mathrm{M} \mathrm{NaOH}$ were then added under stirring. After introducing a volume of $x \mathrm{ml}$ of $0.2 \mathrm{M} \mathrm{NH}_{2} \mathrm{OH} . \mathrm{HCl}$, the mixture was left undisturbed for an hour at room temperature. The as-synthesized samples were then centrifuged at $5000 \mathrm{rpm}$ in 5 minutes and washed with ethanol to remove the surfactant. Finally, the collected precipitate was suspended in ethanol. $\mathrm{Au}-\mathrm{Cu}_{2} \mathrm{O}$ core-shell nanoparticles were synthesized in a similar procedure with a volume of $0.1 \mathrm{ml}$ of gold nanospheres being added to the mixture just before introducing a volume of $x \mathrm{ml}$ of $0.2 \mathrm{M} \mathrm{NH}_{2} \mathrm{OH}$.HCl.

The crystal structure of the synthesized samples was characterized by a Siemens D5005 XRD diffractometer. The morphologies of the synthesized nanoparticles were observed by a Nova nanoSEM 450, a JEOL JEM-1010 transmission electron microscopy (TEM), and a FEI Tecnai $\mathrm{G}^{2} 20$ FEG (HRTEM). The absorption spectra of the samples were measured at room temperature using a Shimadzu UV-Vis-2450PC spectrometer.

\section{Results and discussion}

Figure 1.a. shows a typical XRD pattern of the synthesized $\mathrm{Cu}_{2} \mathrm{O}$ samples. The pattern exhibits four well-resolved diffraction peaks at $29.65^{\circ}, 36.45^{\circ}, 42.35^{\circ}$ and $61.42^{\circ}$ which can be indexed to those of the (110), (111), (200) and (220) planes of the fcc phase of cuprous oxide crystal structure (PDF 050667, ICDD). The lattice constant $a$ was estimated to be $4.077 \pm 0.002 \AA$, which is in good agreement with the standard value of 4.079 Aiven in PDF 05-0667, ICDD. Typical FESEM images of the $\mathrm{Cu}_{2} \mathrm{O}$ particles synthesized by using different amount of reduction agent $\mathrm{NH}_{2} \mathrm{OH} . \mathrm{HCl}$ are shown in Fig.1.bd. The amount of reducing agent $\mathrm{NH}_{2} \mathrm{OH} . \mathrm{HCl}$ plays an important role in shaping the $\mathrm{Cu}_{2} \mathrm{O}$ particles. As the volume of $0.2 \mathrm{M} \mathrm{NH}_{2} \mathrm{OH} . \mathrm{HCl}$ increases from $0.15 \mathrm{ml}$ to $0.30 \mathrm{ml}$ and $0.45 \mathrm{ml}$, the morphology of the $\mathrm{Cu}_{2} \mathrm{O}$ particles changes from cubic to truncated cube and truncated octahedral, respectively, as shown in Fig.1.b-d. The average size of cubic, truncated cube and truncated octahedral $\mathrm{Cu}_{2} \mathrm{O}$ particles was estimated using the FESEM images to be about $220 \pm 20 \mathrm{~nm}, 200 \pm 20 \mathrm{~nm}$ and $280 \pm 18 \mathrm{~nm}$, respectively.
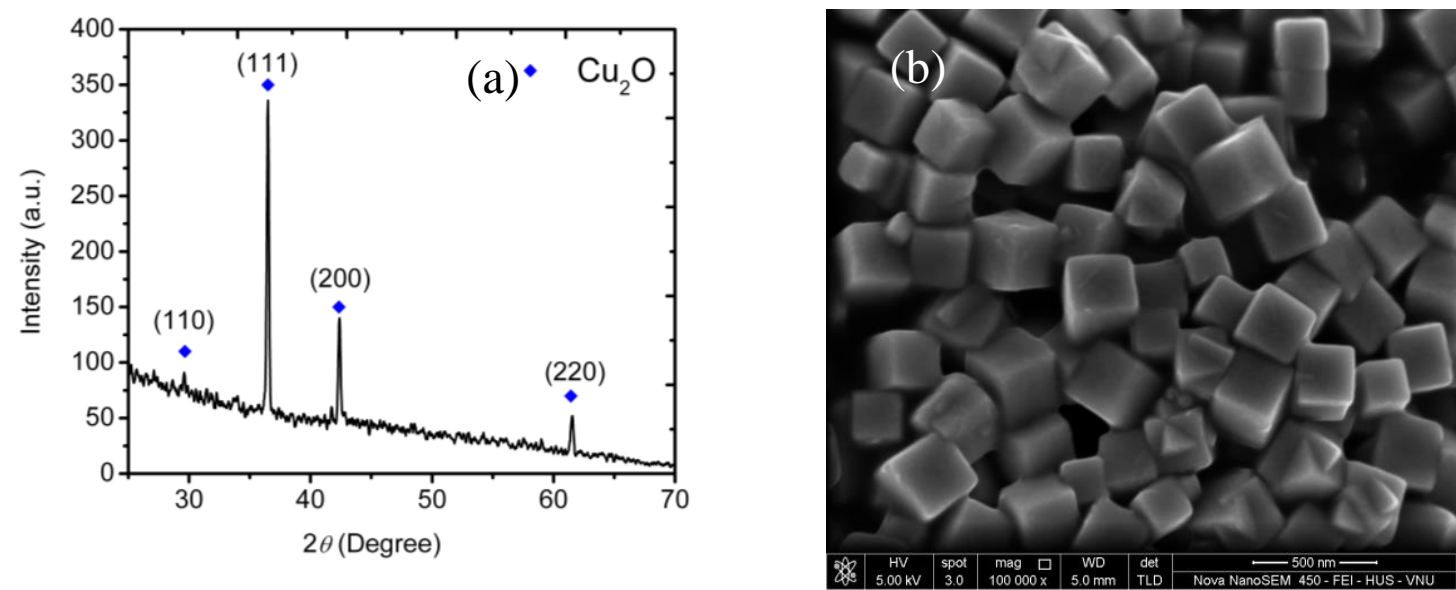

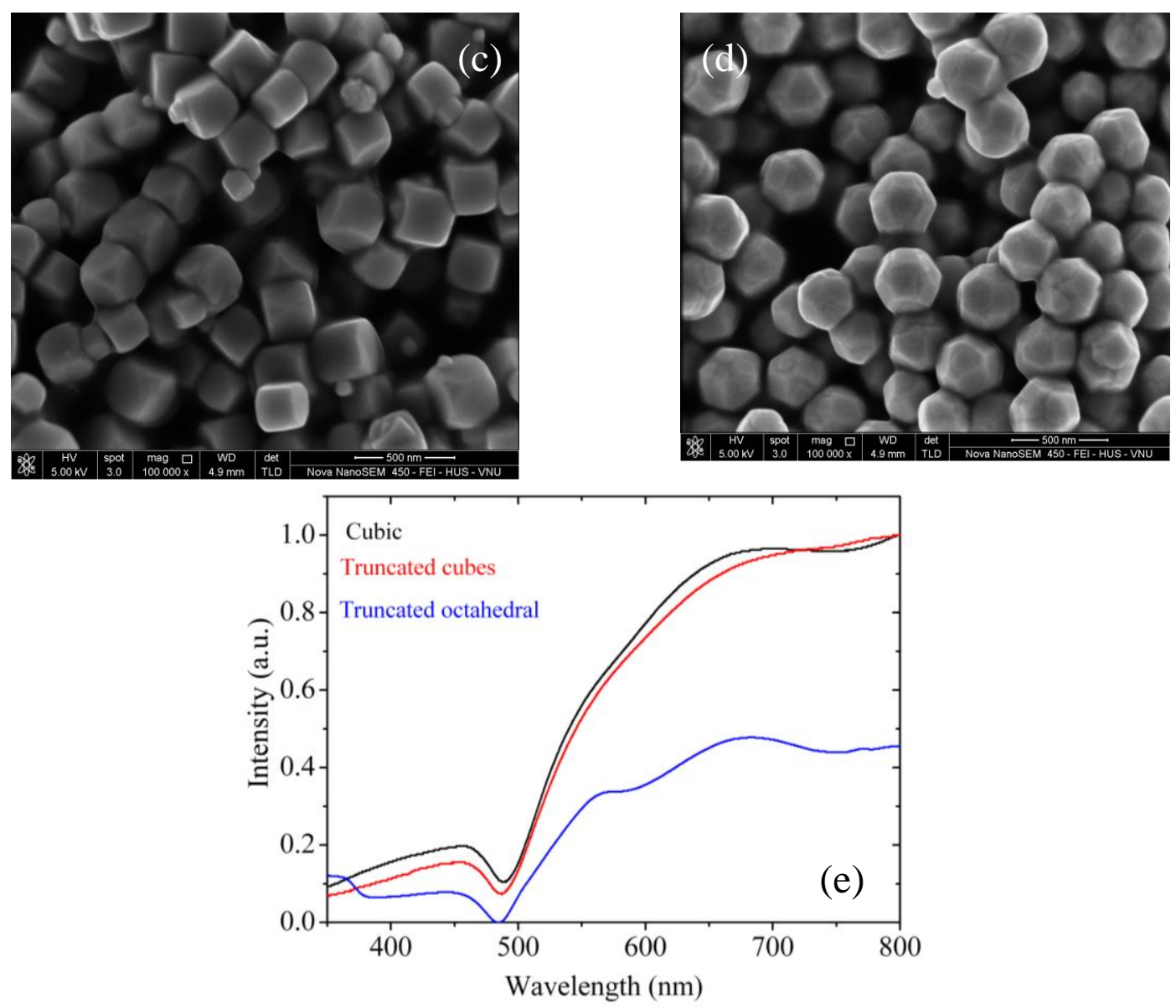

Fig. 1. The typical XRD patterns (a), FESEM images of $\mathrm{Cu}_{2} \mathrm{O}$ synthesized using $0.15 \mathrm{ml}(\mathrm{b}), 0.30 \mathrm{ml}(\mathrm{c})$ and $0.45 \mathrm{ml}(\mathrm{d})$ of $0.2 \mathrm{M} \mathrm{NH}_{2} \mathrm{OH} . \mathrm{HCl}$, extinction spectrum of the synthesized $\mathrm{Cu}_{2} \mathrm{O}$ particles (e).

The extinction spectrum of the synthesized $\mathrm{Cu}_{2} \mathrm{O}$ particle samples are shown in Fig.1.e. Due to a rather large size of $\mathrm{Cu}_{2} \mathrm{O}$ particles, their extinction spectrum is dominated by strong and broad light scattering bands in the red and near infrared wavelength region. In the region below $500 \mathrm{~nm}$, the extinction spectrum exhibits a broad excitation interband absorption band at around $550 \mathrm{~nm}$ [14]. The geometry-dependent nature of the optical property of the synthesized $\mathrm{Cu}_{2} \mathrm{O}$ particles is evident as the extinction spectrum of the truncated octahedral $\mathrm{Cu}_{2} \mathrm{O}$ particles is slightly deference from those of the cubic and truncated cube ones.

The synthesized gold nanoparticles were used as the core of the $\mathrm{Au}-\mathrm{Cu}_{2} \mathrm{O}$ core-shell nanoparticles. Figure 2.a-c show typical XRD pattern, TEM image and UV_Vis spectrum of the synthesized Au nanoparticles, respectively. The XRD pattern exhibits two diffraction peaks at $38.24^{\circ}$ and $44.45^{\circ}$, which match well with the (111) and (200) diffraction peaks of the fcc phase of metallic gold structure (PDF 04-0784, ICDD). As shown in Fig.2.b., the synthesized Au nanoparticles seem to be quasi-spherical in shape and their average size was estimated to be $16.8 \pm 1.9 \mathrm{~nm}$. The UV_Vis spectrum of the synthesized Au nanoparticles exhibits only one absorption peak at about $520 \mathrm{~nm}$ corresponding to the dipole Surface Plasmon Resonance (SPR) of the symmetric spherical gold nanoparticles [9]. 

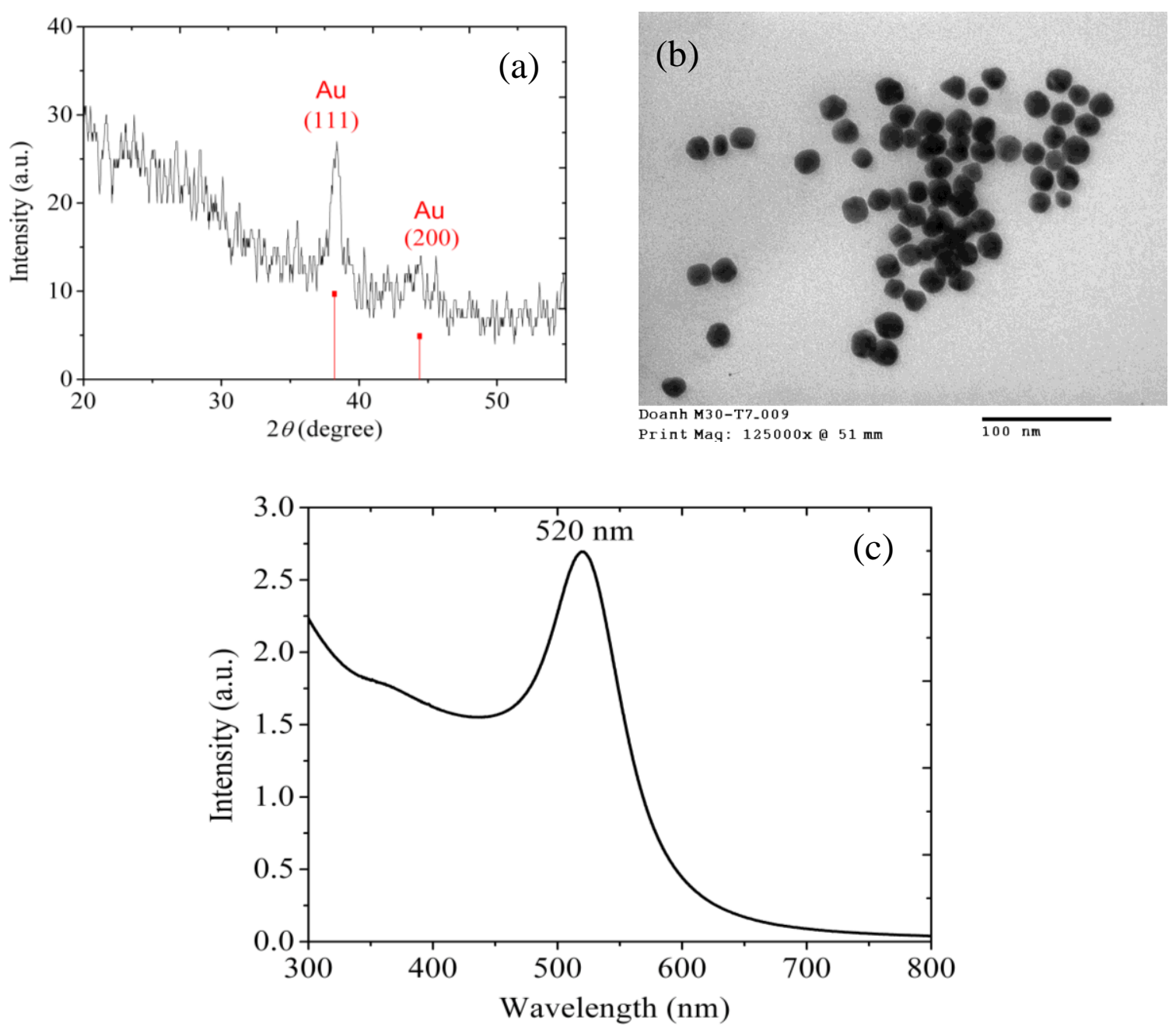

Fig. 2. The typical XRD patterns (a), TEM image (b), and UV_Vis spectrum (e) of the synthesized Au nanoparticles.
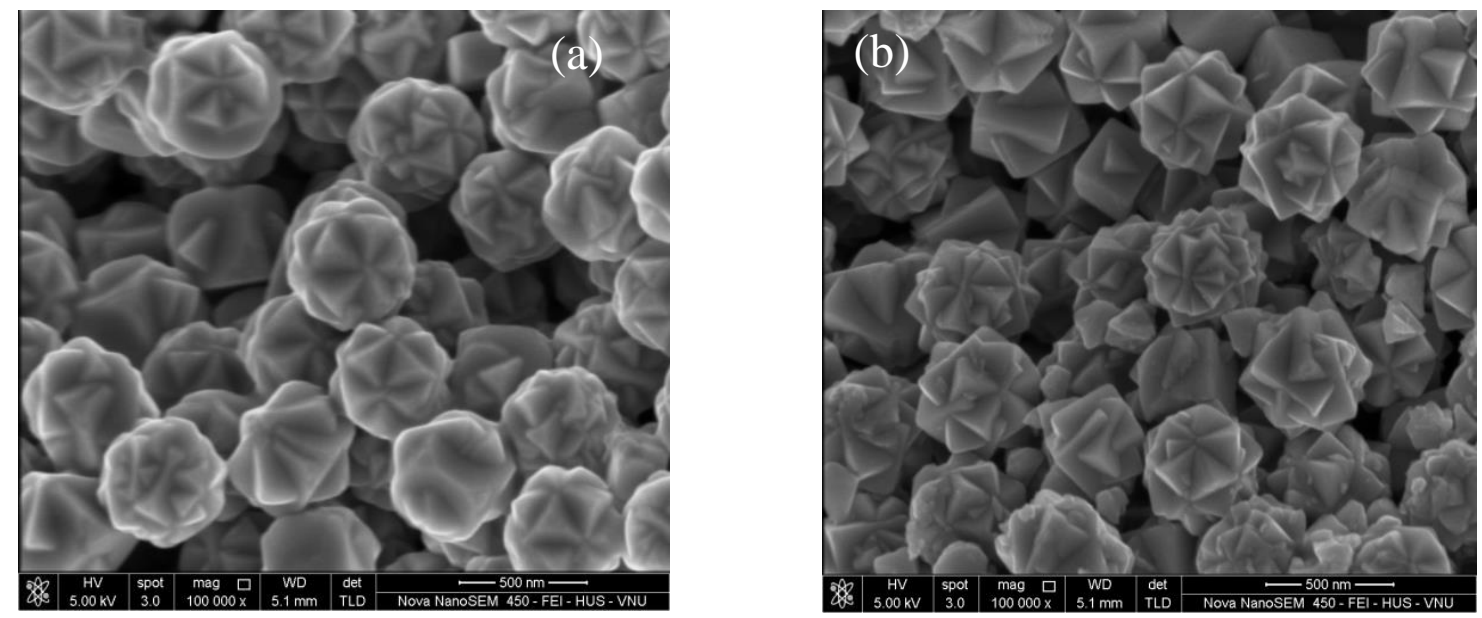

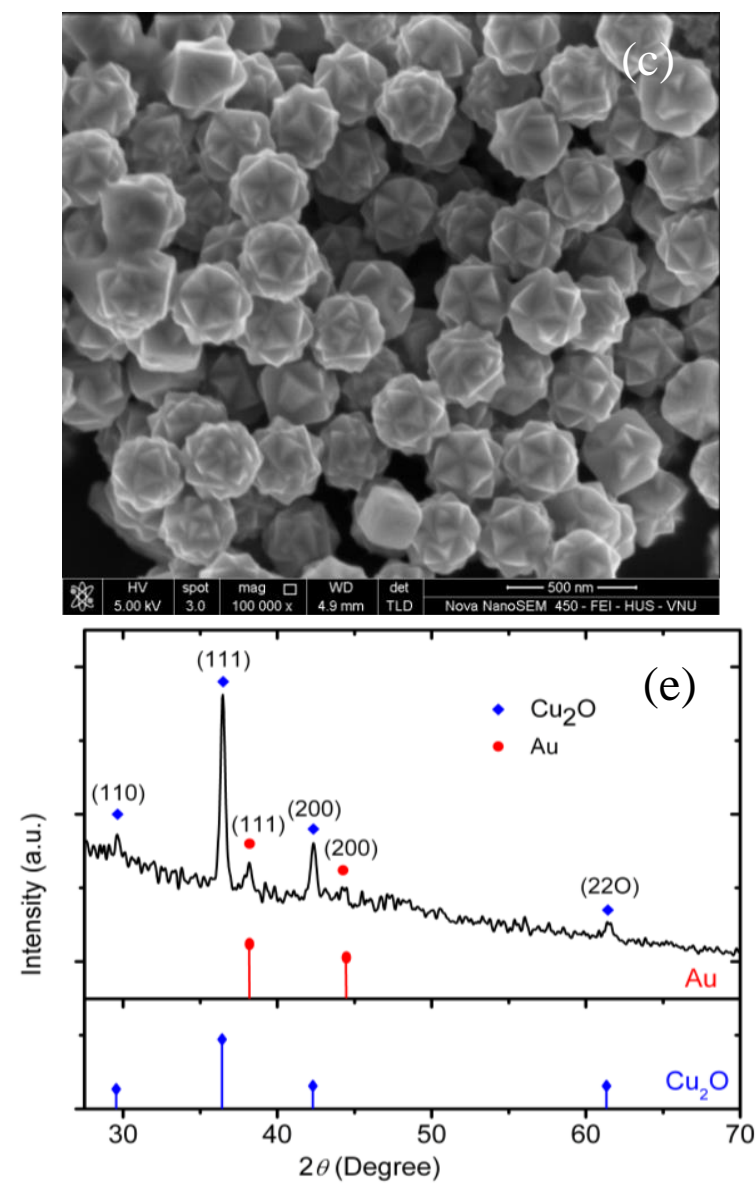

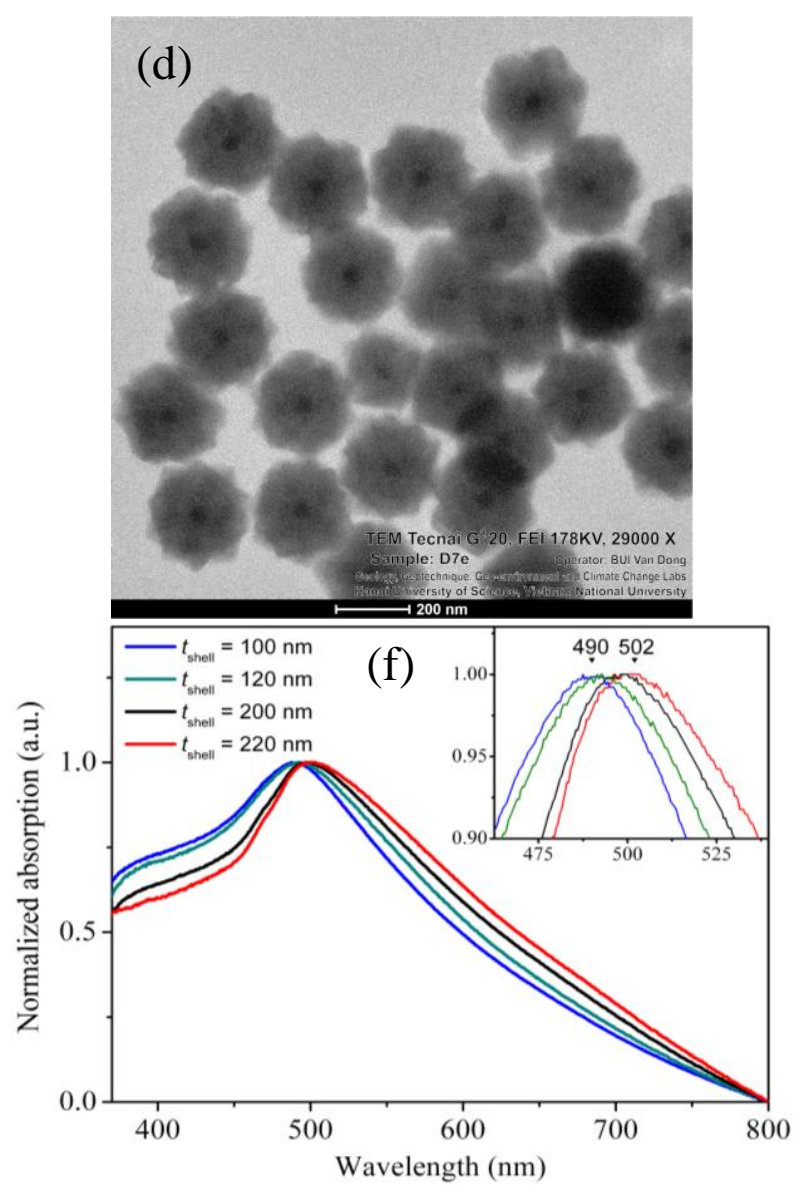

Fig 3. The typical FESEM images of Au-Cu $2 \mathrm{O}$ core-shell particles with different shell thickness $t_{\text {shell }}$ of $220 \mathrm{~nm}$ (a), $200 \mathrm{~nm}$ (b) and $120 \mathrm{~nm}$ (c), TEM image of Au-Cu $\mathrm{Cu}_{2} \mathrm{O}$ core-shell particles with shell thickness $t_{\text {shell }}$ of $100 \mathrm{~nm}$

(d), the XRD patterns (e) and extinction spectrum (f) of the synthesized $\mathrm{Au}-\mathrm{Cu}_{2} \mathrm{O}$ core-shell particles.

The morphology of the synthesized $\mathrm{Au}-\mathrm{Cu}_{2} \mathrm{O}$ core-shell nanoparticles was examined using the FESEM and TEM images. Figures 3.a-d show typical FESEM and TEM image of $\mathrm{Au}-\mathrm{Cu}_{2} \mathrm{O}$ core-shell particles synthesized by using different amount of reduction agent $\mathrm{NH}_{2} \mathrm{OH} . \mathrm{HCl}$. The actual shape of $\mathrm{Au}$ nanoparticles has a strong influence on shaping the morphology of the $\mathrm{Cu}_{2} \mathrm{O}$ shell [10]. Although the $\mathrm{Au}$ nanoparticles appeared as quasi-spherical particles, they are best described as multifacetedtruncated particles [9]. Due to the similar crystal structure and relatively small lattice mismatch of $4.5 \%$ between cuprous oxide and gold, $\mathrm{Cu}_{2} \mathrm{O}$ particles are nucleated and then locally undergo an epitaxial growth only on the surface of the $\mathrm{Au}$ seed resulting in a rough shell of $\mathrm{Cu}_{2} \mathrm{O}$ [11-14]. The SEM images, shown in Figs.2.a-c., reveal the stellated icosahedra morphology of the synthesized Au$\mathrm{Cu}_{2} \mathrm{O}$ particles. The TEM image shown in Fig.3.d. clearly indicates that all the particles possess the core-shell structure with only one $\mathrm{Au}$ core at the center covered entirely by a rough $\mathrm{Cu}_{2} \mathrm{O}$ shell. No particle with multiple cores or coreless was observed. The average thickness $t_{\text {shell }}$ of the $\mathrm{Cu}_{2} \mathrm{O}$ shell of the synthesized Au- $\mathrm{Cu}_{2} \mathrm{O}$ core-shell particle samples shown in Figs.3.a-d. was estimated to be $220.0 \pm$ $7.0 \mathrm{~nm}, 200.0 \pm 7.0 \mathrm{~nm}, 120.0 \pm 8.0 \mathrm{~nm}$ and $100.0 \pm 8.0 \mathrm{~nm}$, respectively. 
Figure 3.e. shows a typical XRD pattern of the synthesized $\mathrm{Au}-\mathrm{Cu}_{2} \mathrm{O}$ core-shell particles. The pattern exhibits several well-resolved diffraction peaks. The diffraction peaks at $29.62^{\circ}, 36.46^{\circ}, 42.34^{\circ}$ and $61.42^{\circ}$ can be indexed to those of the (110), (111), (200) and (220) planes of the fcc phase of cuprous oxide crystal structure (PDF 05-0667, ICDD), respectively. The other diffraction peaks at $38.21^{\circ}$ and $44.40^{\circ}$ match well with the (111) and (200) diffraction peaks of the fcc phase of metallic gold structure (PDF 04-0784, ICDD). Since the $\mathrm{Cu} 2 \mathrm{O}$ shell is in order of a few hundred-nm thick covering entirely the Au nanocore of about $16.8 \pm 1.9 \mathrm{~nm}$ in diameter, the intensities of the diffraction peaks of $\mathrm{Cu}_{2} \mathrm{O}$ shell are much stronger than those of $\mathrm{Au}$ nanocores.

The optical properties of the synthesized $\mathrm{Au}-\mathrm{Cu}_{2} \mathrm{O}$ core-shell particles were investigated by using the UV_Vis spectrum. Figure 3.f. shows the absorption spectrum of the synthesized $\mathrm{Au}-\mathrm{Cu}_{2} \mathrm{O}$ coreshell particles. The spectrum exhibits typical interband absorption band of $\mathrm{Cu}_{2} \mathrm{O}$ shell without any sharp excitonic absorption peak. As the thickness $t_{\text {shell }}$ of the $\mathrm{Cu}_{2} \mathrm{O}$ shell decreases from about $220 \mathrm{~nm}$ to $100 \mathrm{~nm}$, the interband absorption peak undergoes a blue shift from $502 \mathrm{~nm}$ to $490 \mathrm{~nm}$ in good agreement with the results reported elsewhere [15]. No prominent Surface Plasmon Resonance (SPR) absorption peak of $\mathrm{Au}$ nanoparticles is observed due to the fact that the $\mathrm{Cu}_{2} \mathrm{O}$ shell thickness $t_{\text {shell }}$ is too thick.

\section{Conclusions}

$\mathrm{Cu}_{2} \mathrm{O}$ and $\mathrm{Au}-\mathrm{Cu}_{2} \mathrm{O}$ core-shell particles were successfully synthesized using chemical reduction method. The amount of reducing agent $\mathrm{NH}_{2} \mathrm{OH} . \mathrm{HCl}$ has a significant influence on the morphology of the $\mathrm{Cu}_{2} \mathrm{O}$ particles. By varying the amount of $\mathrm{NH}_{2} \mathrm{OH} . \mathrm{HCl}$, several morphologies of the $\mathrm{Cu}_{2} \mathrm{O}$ particles such as cube, truncated cube and truncated octahedral can be precisely fabricated. The extinction spectrum of $\mathrm{Cu}_{2} \mathrm{O}$ particles of several hundred-nm in size is dominated by light scattering in the red and near infrared region.

Due to their similar crystal structure and relatively small lattice mismatch of $4.5 \%, \mathrm{Cu}_{2} \mathrm{O}$ particles are nucleated and then locally undergo an epitaxial growth on the surface of the multi-faceted $\mathrm{Au}$ seed resulting in a rough shell of $\mathrm{Cu}_{2} \mathrm{O}$. Only the characteristic interband absorption band of the $\mathrm{Cu}_{2} \mathrm{O}$ shell is observed in the absorption spectrum of the synthesized $\mathrm{Au}-\mathrm{Cu}_{2} \mathrm{O}$ core-shell particles. The absorption band undergoes a blue shift from $502 \mathrm{~nm}$ to $490 \mathrm{~nm}$ as the shell thickness decreases from $220 \mathrm{~nm}$ to $100 \mathrm{~nm}$. Au-Cu $\mathrm{Cu}_{2} \mathrm{O}$ core-shell particles with a much thinner shell would be necessary to investigate the SPR of Au nanocores.

\section{Acknowledgments}

Financial support from VNU Hanoi University of Science (Project TN. 16.05) is gratefully acknowledged. The authors wish to thank the Center for Materials Science and the Department of Solid State Physics at the Faculty of Physics, VNU Hanoi University of Science, for making some experimental facilities such as SIEMENS D5005 XRD diffractometer, FEI Nova nanoSEM 450, Shimadzu UV-Vis-2450PC and Varian Carry 5000 spectrometers available to us.

\section{References}

[1] C. H.Kuo, M. H. Huang, Morphologically controlled synthesis of $\mathrm{Cu}_{2} \mathrm{O}$ nanocrystals and their properties, Nano Today, 5, 2010, pp. $106-116$. 
[2] H. Zhang, C.Shen, S. Chen, Z. Xu, F. Liu, J. Li and H. Gao, Morphologies and microstructures of nano-sized $\mathrm{Cu}_{2} \mathrm{O}$ particles using a cetyltrimethylammonium template, Nanotechnology, 16, 2005, pp. 267-272.

[3] Y. H. Won and L. A. Stanciu, $\mathrm{Cu}_{2} \mathrm{O}$ and $\mathrm{Au} / \mathrm{Cu}_{2} \mathrm{O}$ Particles: Surface Properties and Applications in Glucose Sensing, Sensors, 12, 2012, pp. 13020 - 13033.

[4] M. Basu, A. K. Sinha, M. Pradhan, S. Sarkar, A. Pal, C.Mondal, and T. Pal, Methylene Blue $\mathrm{Cu}_{2} \mathrm{O} \mathrm{Reaction}$ Made Easy in Acidic Medium, J. Phys. Chem. C,116,2012, pp. 25741-25747.

[5] M. Hara, T. Kondo, M. Komoda, S. Ikeda, K. Shinohara, A. Tanaka, J. N. Kondo, K. Domen, $\mathrm{Cu}_{2} \mathrm{O}$ as a photocatalyst for overall water splitting under visible lightIrradiation, Chem. Commun., 1998,pp. 357 - 358.

[6] P. Poizot, S. Laruelle, S. Grugeon, L. Dupont, J. M. Tarascon, Nano-sized transition-metal oxides as negativeelectrode materials for lithium-ion batteries, Nature, 407, 2000, pp. 496 - 499.

[7] L. Gou, C. J.Murphy, Solution-Phase Synthesis of $\mathrm{Cu}_{2} \mathrm{O}$ Nanocubes, Nano. Lett., volume 3, issue 2, 2003 , pp. 231-234.

[8] Y. Zhong, Y. Li, S. Li, S. Fenga and Y. Zhang, Nonenzymatic hydrogen peroxide biosensor based on four different morphologies of cuprous oxide nanocrystals, RSC Adv., 4, 2014, pp. 40638 - 40642.

[9] N. A. Bang, P. T. Thom and H. N. Nhat, A comparative study of classical approaches to surface plasmon resonance of colloidal gold nanorods, Gold Bulletin, Volume 46, Issue 2, 2013, pp. 91-96.

[10] C. H. Kuo, T. E. Hua and M. H. Huang, Au Nanocrystal-Directed Growth of $\mathrm{Au}_{-} \mathrm{Cu}_{2} \mathrm{O} \mathrm{Core}_{-} \mathrm{Shell}$ Heterostructures with Precise Morphological Control, J. Am. Chem. Soc. 131, 2009, pp. 17871-17878.

[11] W. C. Wang, L. M. Lyu and M. H. Huang, Investigation of the Effects of Polyhedral Gold NanocrystalMorphology and Facets on the Formation of $\mathrm{Au}-\mathrm{Cu} 2 \mathrm{O}$ Core-Shell Heterostructures, Chem. Mater., 23, 2011, pp. 2677-2684.

[12] K. H. Yang, S. C. Hsu and M. H. Huang, Facet-Dependent Optical and Photothermal Properties of Au@ $\mathrm{Ag}-\mathrm{Cu}_{2} \mathrm{O}$ Core-shell Nanocrystals, Chem. Mater., 28, 2016, pp. 5140 - 5146.

[13] L. Zhang, D. A. Blom and H. Wang, $\mathrm{Au}-\mathrm{Cu}_{2} \mathrm{O}$ Core-Shell Nanoparticles: A Hybrid Metal Semiconductor Heteronanostructure with Geometrically Tunable Optical Properties, Chem. Mater., 23 (20), 2011, pp. 45874598.

[14] Y. Pan, S. Deng, L. Polavarapu, N. Gao, P. Yuan, C. H. Sow and Q. H. Xu, Plasmon-enhanced photocatalytic properties of $\mathrm{Cu}_{2} \mathrm{O}$ nanowire-Au nanoparticle assemblies, Langmuir, 28, 2012, pp. 12304-12310.

[15] L. Zhang and H. Wang, Cuprous Oxide Nanoshells with Geometrically Tunable Optical Properties, ACS Nano, 5(4), 2011, pp. 3257-3267. 